\title{
Visualization of extracellular polymeric substances in Aspergillus niger biofilms using lectin-conjugates and confocal laser scanning microscopy (CLSM)
}

Aswathy Shailaja ${ }^{1}$, Julia Kerrigan ${ }^{2}$, Terri Bruce ${ }^{3}$ and Patrick Gerard ${ }^{4}$

${ }^{1}$ Clemson University, Central, South Carolina, United States, ${ }^{2}$ Clemson University, Clemson, South Carolina, United States, ${ }^{3}$ Clemson University, South Carolina, United States, ${ }^{4}$ Clemson University, United States

Aspergillus niger is a filamentous fungus that adheres to different substrate surfaces and form biofilms consisting of dense hyphal networks embedded in a self-produced gelatinous matrix composed of extracellular polymeric substance (EPS). The important features of EPS include the capability to adhere to the substrate, cellular cohesion, ability to provide three-dimensional architecture of biofilm, ability to provide protection from antimicrobial agents and host immune system (Baillie and Douglas 2000; Jin et al. 2005) and serving as a nutritional resource. The EPS mainly contains exopolysaccharides. The objective of this study was to visualize and assess the different exopolysaccharides structure in this extracellular polymeric substance using a combination of two different fluorescent-labeled lectin probes, Erythrina cristagalli (ECA)-FITC and Canavalia ensiformis (Con A)-TRITC. Each lectin is a unique protein that binds to specific a carbohydrate moiety and is classified based on these terminal sugars to which they are binding. Exopolysaccharides are imaged according to their distinct fluorescence color with the help of confocal laser scanning microscopy (CLSM). The biomass, average thickness, and roughness of biofilms were calculated from the Z-stack images using the computer program COMSTAT. A statistically significant difference was observed in the biomass $\left(\mu \mathrm{m}^{3} / \mu \mathrm{m}^{2}\right)$, average thickness $(\mu \mathrm{m})$, and roughness of the biofilm treated with the two different lectin probes indicating the presence of a higher amount of galactose and $\beta-1,4 \mathrm{~N}$-acetylgalactosamine ( $\beta 4 \mathrm{GalNAc}$ ) when compared to the mannose and glucose moieties in the EPS of A. niger biofilm. The combination of two lectinfluorescent probe method staining should help better characterization of $A$. niger biofilms in terms of their heterogeneity with regards to the EPS production.

Keywords: A. niger biofilms, extracellular polymeric substances (EPS), exopolysaccharides, heterogeneity, galactose, glucose, lectin -fluorescent probe, $\beta-1,4 \mathrm{~N}$-acetylgalactosamine, mannose. 
Acknowledgement: Clemson University Core Incentivized Access (CU-CIA) program (2019) for microscopy

project funding.

\section{References}

Baillie, G. S., and Douglas, L. J. 2000. Matrix polymers of Candida biofilms and their possible role in biofilm resistance to antifungal agents. Journal of Antimicrobial Chemotherapy. 46:397-403 Available at: https://doi.org/10.1093/jac/46.3.397.

Flemming, H. C., and Wingender, J. 2010. The biofilm matrix. Nature Reviews Microbiology. 8.

Jin, Y., Zhang, T., Samaranayake, Y. H., Fang, H. H. P., Yip, H. K., and Samaranayake, L. P. 2005. The use of new probes and stains for improved assessment of cell viability and extracellular polymeric substances in Candida albicans biofilms. Mycopathologia. 159:353-360 Available at: https://doi.org/10.1007/s11046-0046987-7.

Mitchell, K. F., Zarnowski, R., and Andes, D. R. 2016a. Fungal Super Glue: The Biofilm Matrix and Its Composition, Assembly, and Functions. PLoS Pathogens. 12:e1005828 Available at: https://link.gale.com/apps/doc/A476956084/AONE?u=clemsonu_main\&sid=AONE\&xid=c88604d9.

Mitchell, K. F., Zarnowski, R., and Andes, D. R. 2016b. The extracellular matrix of fungal biofilms. Advances in Experimental Medicine and Biology. 931.

Rajendran, R., Williams, C., Lappin, D. F., Millington, O., Martins, M., and Ramage, G. 2013. Extracellular DNA Release Acts as an Antifungal Resistance Mechanism in Mature Aspergillus fumigatus Biofilms. Eukaryotic Cell. 12:420 Available at: http://ec.asm.org/content/12/3/420.abstract.

Ramage, G., Rajendran, R., Sherry, L., and Williams, C. 2012. Fungal Biofilm Resistance. International Journal of Microbiology. 2012:528521 Available at: https://doi.org/10.1155/2012/528521.

Zarnowski, R., Westler, W. M., Lacmbouh, G. A., Marita, J. M., Bothe, J. R., Bernhardt, J., et al. 2014. Novel Entries in a Fungal Biofilm Matrix Encyclopedia eds. Jose Lopez-Ribot and Judith Berman. mBio. 5:1333 Available at: http://mbio.asm.org/content/5/4/e01333-14.abstract. 